\title{
Música como discurso: uma \\ perspectiva a partir da filosofia do círculo de Bakhtin
}

\author{
Silvia C. N. Schroeder \\ (USP) \\ Jorge L. Schroeder \\ (UNICAMP)
}

Resumo: Neste trabalho pretendemos apresentar um modo de conceber a música que utiliza, como base epistemológica, a teoria enunciativo-discursiva de pensadores do círculo de Mikhail Bakhtin. A partir da proposta dos autores para a investigação da língua em funcionamento, utilizamos alguns de seus conceitos-chave para observar a música através de uma mesma perspectiva, apontando ainda a possibilidade de estender esse olhar a outras linguagens artísticas.

Palavras-chave: Música, Arte, Círculo de Bakhtin, Discurso, Enunciação.

MUSIC AS DISCOURSE: A PERSPECTIVE FROM THE PHILOSOPHY OF THE BAKHTIN CIRCLE

Abstract: In this work we intend to present a way to conceive the music that uses, as epistemological base, the enunciative-discoursive theory of the Bakhtin Circle's thinkers. From the proposal of the authors for the investigation of language in functioning, we use some of its key concepts to observe the music through one equal perspective, pointing yet the possibility to extend this approach to other artistic languages.

Keywords: Music, Art, Bakhtin Circle, Discourse, Enunciation. 


\section{Introdução}

A música, assim como as demais linguagens artísticas', por sua forte presença nas sociedades, tem sido objeto de reflexão para várias áreas do conhecimento. Filósofos, historiadores, sociólogos, antropólogos, linguistas, educadores, psicólogos e psicanalistas estão entre os vários profissionais que se aventuram, com mais ou menos propriedade, mais ou menos ousadia, a ponderar sobre música. No entanto é possível perceber, ao nos colocarmos em contato com essa produção, que, grosso modo, ela se organiza basicamente em duas principais vertentes. Chamaremos aqui essas vertentes, até mesmo por falta de termos mais apropriados, de visão "de fora” e "de dentro" do campo artístico.

A visão "de fora" (mais comumente pretendida por áreas como a sociologia, a história, algumas tendências da antropologia, psicologia, psicanálise e educação) se ocupa em observar como algumas questões mais diretamente ligadas às preocupações próprias de cada área se manifestam no terreno artístico. Quando a sociologia pretende observar como se dá a circulação da produção fonográfica, ou os processos de valorização e legitimação de quadros ou esculturas, por exemplo; ou quando a cinesiologia pretende descrever o corpo de um bailarino dançando, podemos dizer que, embora as manifestações artísticas estejam envolvidas, elas não são tomadas exatamente como o alvo das investigações propostas. Nesses casos, a música, as artes visuais, ou a dança, são apenas os locais onde se dá um processo de investigação com objetivos bem específicos, ou um motivo para sua explicitação - econômico, no primeiro caso, sociocultural, no segundo, e terapêutico, no terceiro. Isto acarreta, sem dúvida, um rol de informações adicionais importantes para o campo das artes, propícias a complementar o conhecimento propriamente artístico, mas que dele não faz outro uso a não ser como justificativa ou ilustração para a produção de conhecimentos

\footnotetext{
1 Embora nosso foco, neste artigo, seja a linguagem musical, ampliaremos a discussão, sempre que possível, para o campo artístico em geral, por entendermos que, no que tange às questões aqui levantadas, a música e as demais artes operam de modo bastante semelhante e, por vezes, com certa cumplicidade.
} 
próprios ligados a cada área específica (sociológica, psicológica, antropológica etc.).

Já a visão "de dentro" (praticada, além das teorias das artes em suas várias linguagens, principalmente pela filosofia estética, teoria literária, crítica de arte e arte-educação) se esforça em explicitar os modos de organização das obras, as derivações e influências entre artistas, além de seus processos criativos e procedimentos técnicos. Este é o caso de muitas explanações feitas por estudiosos de outras áreas que, em algum momento de suas vidas, estudaram alguma arte, tais como o cineasta Eric Rohmer (1997) ou o filósofo Edward Said (2003) quando resolveram escrever sobre música.

Além disso, a própria área artística algumas vezes se utiliza de conhecimentos gerados em outros campos, como é o caso do uso frequente da física acústica pela música, da fisiologia pela dança, ou da ótica e da geometria pela pintura, para tentar aprofundar os conhecimentos sobre as próprias produções.

Contudo, num caso ou no outro ("de dentro" ou "de fora"), mesmo se levarmos em conta a infinidade de nuances existente entre os dois pólos, é possível inferir, com maior ou menor dificuldade, a opção escolhida entre um deles nos discursos sobre a arte. Ainda que várias tentativas estejam sendo feitas para atenuar o distanciamento que insiste em se manter entre o "dentro" e o "fora" da arte (como é o caso, além dos já citados, de Lévi-Strauss 1997, Clifford Geertz 1997, Herbert Marcuse 1999, Jean-Marie Guyau 2009, Vera Zolberg 2006 e tantos outros), para alguém que se situa "dentro" da arte são facilmente perceptíveis os vazios não preenchidos pelos pontos de vista dos que habitam o "fora", e vice-versa².

Tentamos avaliar essa situação não como uma impossibilidade absoluta de se poder integrar as duas visões, mas como essa integração fica difícil sem uma alteração nos fundamentos, nos pontos de vista sobre o assunto. A necessidade de pensar diferente para se desvencilhar da obrigatoriedade de ter que se posicionar

\footnotetext{
${ }^{2}$ Para um aprofundamento nesse assunto, ver Schroeder (2004).
} 
ou "dentro" ou "fora" do campo artístico foi o que nos impulsionou a tomar outro caminho. A partir, então, de pensadores que questionaram algumas falsas dicotomias (tais como o indivíduo e a sociedade, o fato e o contexto, a emoção e a cognição, a regra e a transgressão, ruptura e continuidade etc.) através de uma mudança de fundamentação epistemológica, pensamos ser possível também contribuir para o questionamento desta, em nossa opinião, falsa dicotomia do "dentro" e do "fora" na arte como um todo e na música em particular. E dos vários autores disponíveis para esse empreendimento, decidimos por concentrarmo-nos neste artigo em um grupo que muito tem contribuído para nossos estudos e pesquisas na área da música, o circulo do pensador russo Mikhail Bakhtin, conhecido como o Círculo de Bakhtin ${ }^{3}$, pelos estudiosos de suas obras ${ }^{4}$. Esse grupo de pensadores se interessou pelas produções simbólicas de modo geral, as quais eles denominavam "sistemas ideológicos" ou "sistemas axiologicamente marcados", dando especial ênfase à língua e à literatura. Tentaremos explicitar a partir de agora alguns princípios básicos da teoria do discurso e da enunciação, abordados em seus trabalhos sobre a filosofia da linguagem, e com eles explorar algumas questões musicais também básicas, mostrando como suas teorias ajudam na diluição dessa oposição.

\section{A música e a perspectiva discursiva}

Embora o Círculo de Bakhtin tenha criado seus principais conceitos tomando como objeto a linguagem verbal, acreditamos que muitos desses conceitos iluminam questões importantes sobre a música e a arte, ou seja, também sobre outras linguagens. Assim sendo, partiremos de conceitos propostos pelo Círculo, principalmente do próprio Bakhtin e de Voloshinov, mostrando

${ }^{3}$ O Círculo de Bakhtin era composto por vários intelectuais, entre eles, além do próprio Mikhail Bakhtin, o filósofo Matvei I. Kagan, o biólogo Ivan I. Kanaev, a pianista Maria V. Yudina, o estudioso de literatura Lev V. Pumpianski, o lingüista e músico Valentin N. Voloshinov e o advogado e educador Pavel N. Medvedev, que se reuniram regularmente em Nevel e depois em Vitebsk entre 1919 e 1929 (Faraco, 2009, p.13).

${ }^{4}$ Ver, por exemplo, Faraco (2009), Brait (2009) e Paula e Stafuzza (2010). 
algumas homologias e analogias possíveis que consideramos elucidativas e fundamentais para o pensamento artístico, especialmente musical.

De acordo com Voloshinov (Bakhtin/Voloshinov 2002) ${ }^{5}$, as teorias da linguagem no início do século XX de modo geral se filiavam a duas principais e opostas correntes. A primeira, por ele denominada "objetivismo abstrato", tinha um caráter estruturalista e considerava a língua um sistema fechado, regido por leis claras e intransponíveis, socialmente partilhadas e estáveis. Fatores externos eram tidos como irrelevantes, pois a língua era vista como um produto acabado a ser transmitido de geração a geração. Já para a segunda corrente, a qual Voloshinov denominou "subjetivismo idealista", a língua era uma criação individual e contínua, que não se submetia a normas de qualquer tipo. Tratava-se, portanto, de uma visão romântica da linguagem como expressão interior do falante. Para Voloshinov, mas também para os demais integrantes do Círculo de Bakhtin, embora essas duas perspectivas tivessem razão em vários pontos, nenhuma delas, contudo, dava conta do fenômeno total da linguagem, já que a primeira destacava apenas os seus aspectos formais, estruturais, e a segunda, os seus aspectos individuais, expressivos, criativos.

Essa mesma disputa entre a forma e a estrutura, a expressão e a criação, encontramos nas abordagens sobre a linguagem musical. De um lado, temos os que defendem a música como sendo essencialmente um modo de expressão do indivíduo, que nada deve a leis ou normas externas à psicologia individual, preocupando-se em investigar principalmente as obras primas e os gênios criativos (equivalente ao "subjetivismo idealista"), e, de outro, os que vêem na música sistemas sujeitos a regras, submissos a normas e procedimentos previamente existentes, e se voltam ao estudo formal e teórico musical (muito próximos ao "objetivismo abstrato"). Esses dois modos de entender a música, é importante que

\footnotetext{
${ }^{5}$ Adotamos neste texto a posição de alguns estudiosos atuais do Círculo que atribuem autorias distintas para algumas obras do grupo. Outros estudiosos consideram todas como produções do próprio Bakhtin. Nossa opção pode ser justificada a partir das reflexões que Faraco (2009) faz sobre a questão da autoria das obras (principalmente p. 11 e ss), mas também Bubnova (2010, p. 21) e Morson, Emerson (2008, p. 120 e ss). Contudo, nas referências iremos respeitar a atribuição das autorias de acordo com as edições brasileiras utilizadas.
} 
se diga, não apenas foram característicos de períodos passados, pensadores ou propostas estéticas específicas, mas coexistem na contemporaneidade. Em outras palavras, a disputa entre a prevalência de aspectos sociais e normativos, ou individuais e expressivos, permanece ainda hoje e encontra ecos na produção artística musical, na crítica musical e em propostas educacionais para a música .

Como alternativa a essas visões parciais, o Círculo de Bakhtin propõe uma abordagem enunciativo-discursiva da linguagem. Para esses autores, a língua só pode ser abarcada quando em uso ou em funcionamento. Nem o sistema enquanto uma abstração, nem as leis da psicologia individual oferecem subsídios suficientes para um entendimento da linguagem. Vejamos, então, o que caracteriza o funcionamento linguístico para essa perspectiva e como podemos trazer isso para a música.

\subsection{A noção de enunciado e os gêneros do discurso}

O uso da língua, para Bakhtin (2000), se dá em forma de enunciados concretos e únicos (orais ou escritos), proferidos por falantes específicos em situações particulares. Esses enunciados, que possuem características definidas, dão origem aos discursos, que são "os efeitos de sentido produzidos por enunciados levando-se em conta o contexto - social, cultural, histórico - onde são produzidos" (Schroeder, 2009, p. 45). O enunciado é, portanto, a “unidade real da comunicação verbal” (Bakhtin, 2000, p. 287), o que deve ser tomado como ponto de partida para qualquer reflexão ou análise da linguagem. As palavras e as orações, unidades da língua enquanto sistema, estão sempre a serviço da

\footnotetext{
${ }^{6}$ No âmbito da educação, por exemplo, temos claramente a cisão entre uma linha de ensino de música bem tradicional, cuja principal preocupação é técnica, praticada sobretudo nos conservatórios, algumas escolas livres e graduações em música, e uma linha mais "alternativa", preocupada sobretudo com a criação livre e espontânea, praticada principalmente nas escolas de ensino regular e em algumas propostas do ensino nãoformal. Também é possível perceber essas tendências em alguns autores consagrados da educação musical, como, por exemplo, de um lado, Gainza (1988) que defende um desenvolvimento da consciência corporal para adaptar os estudantes às regras tradicionais da música, ou, de outro, Schafer (2000) que propõe o desenvolvimento praticamente espontâneo da compreensão musical.
} 
enunciação, não tendo existência significativa fora dos enunciados concretamente produzidos. Aqui já podemos perceber um abrandamento da oposição entre submissão à regra e liberdade de invenção. Tomando os enunciados como unidades de sentido das línguas, eles devem obedecer a certas regras de organização para serem compreendidos; por sua vez são únicos nas suas emissões, visto estarem atrelados diretamente a certas situações concretas irrepetíveis de onde surgem.

Outra particularidade de todo enunciado é que ele é sempre dirigido a alguém (um interlocutor) e suas fronteiras são definidas pela alternância dos falantes, ou seja, um enunciado termina quando completa um sentido e esse procedimento provoca uma atitude no interlocutor que Bakhtin denomina "responsiva”. Diferente da "resposta” de um diálogo face a face, embora a inclua, a atitude responsiva pode se manifestar de várias maneiras distintas: na forma de outros enunciados, numa outra linguagem ou numa ação, imediatamente ou muito tempo depois do enunciado ouvido (ou lido, ou visto).

Além disso, embora cada enunciado tomado isoladamente seja individual, “cada esfera de utilização da língua elabora seus tipos relativamente estáveis de enunciados, denominados gêneros do discurso" (Bakhtin, 2000, p. 279, grifos do autor), os quais podem ser mais padronizados (cumprimentos, falas cotidianas, documentos oficiais, ordens militares etc.) ou mais criativos (gêneros literários ou propagandísticos, por exemplo). Ou seja, há uma dimensão social em todo enunciado, ainda que ele seja proferido por um único indivíduo. A própria aquisição da linguagem, de acordo com essa teoria, se dá pelo contato com enunciados alheios e não com a língua enquanto sistema. A possibilidade de produzir enunciados, nesse sentido - não apenas na fase de aquisição da língua, mas durante toda a vida -, pressupõe a existência de outros enunciados produzidos anteriormente:

O próprio locutor como tal é, em certo grau, um respondente, pois não é o primeiro locutor, que rompe pela primeira vez o eterno silêncio de um mundo mudo, e pressupõe não só a existência do sistema da língua que utiliza, mas também a existência dos enunciados anteriores - emanantes dele mesmo ou do outro - aos quais seu próprio enunciado está vinculado por algum tipo de relação (fundamenta-se neles, polemiza com eles), pura e 
simplesmente ele já os supõe conhecidos do ouvinte. Cada enunciado é um elo da cadeia muito complexa de outros enunciados (Bakhtin, 2000, p. 291).

Há, portanto, um tipo de relação explícita ou implícita entre os enunciados, que Bakhtin chama de relação dialógica. Esse conjunto de relações dialógicas entre enunciados vivos, conforme atesta o autor, configura uma verdadeira cadeia discursiva verbal, da qual cada enunciado é um elo.

Trazendo essa perspectiva sobre a linguagem verbal para a música, várias questões se iluminam. Assim como na língua, podemos dizer que também aqui são as obras concretamente produzidas (os "enunciados musicais") que permitem o acesso das pessoas à fruição e compreensão das músicas. Os sistemas, as regras formais, as escolas estilísticas só são acessíveis, só tem existência por intermédio das obras concretas. Fora delas, não passam de abstrações, possibilidades virtuais que podem ou não vir a se realizarem.

Analogamente ao funcionamento linguístico, também todo enunciado musical é dirigido a alguém, pressupõe um interlocutor - presente ou ausente, real ou imaginário - que de algum modo lhe será um respondente. A resposta aos enunciados musicais, também como na língua, nem sempre é imediata e materialmente visível, pois pode ser desde uma simples fruição da obra ${ }^{7}$ ou uma manifestação verbal (como um elogio, saudação ou cumprimento) até a criação de outra obra em algum outro momento ou numa outra linguagem artística. Esse jogo de respostas a enunciados artísticos através da criação de outras obras, aliás, é uma característica muito presente no campo artístico de modo geral, não apenas na música. É o caso, por exemplo, de livros que viram filme - como o filme Morte em Veneza, de Luchino Visconti, baseado no livro de Thomas Mann de mesmo nome -, quadros que viram música - como a suíte "Quadros de uma Exposição", de Modest Mussorgsky, baseada na exposição de quadros do arquiteto e pintor Viktor Hartmann - etc.

7 É importante assinalar que, para Bakhtin (2000), a compreensão de um enunciado é sempre uma atitude "responsiva ativa", daí porque a fruição também pode ser considerada uma resposta a uma obra de arte ou musical. 
Embora cada música seja única, também aqui podemos falar em modos estáveis de produção musical, já que as músicas sempre se filiam, com maior ou menor ênfase, a algum gênero de discurso artístico. Não fosse assim, não conseguiríamos "classificar" as obras em escolas ou estilos, por exemplo. Essa classificação nada mais é do que uma busca de traços comuns entre grupos de obras de um período, uma região ou um autor, de relações dialógicas (responsivas) entre as obras que se filiam a gêneros idênticos, aparentados ou mesmo distanciados. Há, então, uma dimensão social em toda produção musical: fazer música pressupõe o domínio de gêneros musicais coletivamente construídos. Isso não significa que não haja, na música, espaço para a criação, para a colocação da individualidade do artista. Segundo Bakhtin (2000), somos mais criativos exatamente nos gêneros do discurso que mais dominamos ("É de acordo com nosso domínio dos gêneros que usamos com desembaraço que descobrimos mais depressa e melhor nossa individualidade neles...", p. 304) e muitos gêneros se prestam a "reestruturações criativas", sendo contudo muito rara a criação individual de um novo gênero. A noção de criatividade, dessa forma, está menos ligada à invenção de algo totalmente novo e mais ao manejo original de materiais e fórmulas já existentes.

Pensamos que também na música as noções de criatividade e originalidade se renovam a partir da ideia de gênero do discurso. Muitos músicos atingiram a maestria reestruturando criativamente gêneros e sistemas já bastante usados e não propriamente criando um gênero novo ou uma nova gramática. Um exemplo paradigmático na história da música ocidental é o compositor J. S. Bach, considerado quase unanimemente um dos maiores músicos de todos os tempos. Sabemos, entretanto, que o grande feito desse compositor foi levar às últimas consequências o sistema composicional já consolidado em sua época (o sistema tonal) e não "inventar" um novo sistema, por exemplo. Bach explorou exaustivamente praticamente todas as possibilidades dentro do que já se fazia na época barroca, e sua genialidade (e originalidade) repousa nesse fato, o que o tornou um modelo de procedimentos musicais a serem seguidos.

Outro exemplo, embora contrastante, é o do compositor Arnold Schoenberg, considerado o inventor do sistema musical chamado dodecafônico, 
do qual veio depois derivar um outro: o sistema serial. Embora esse sistema de organização composicional fosse invenção de um só músico, evidentemente desenvolvido posteriormente pela comunidade de músicos situados ao seu redor, entre eles vários de seus alunos, podemos dizer que o gênero de discurso musical ao qual se filiou já fazia parte de uma proposta estética da vanguarda musical desde o final do século XIX. É possível dizer, portanto, que Schoenberg propôs um sistema ou atualizou uma técnica filiada a uma proposta estética mais ampla, derivada de vários outros empreendimentos composicionais que incluíam outros compositores (como Paul Hindemith, Bela Bartók, Igor Stravinsky, Sergei Prokofiev, dentre vários outros).

Mesmo nas poéticas que aspiram a uma invenção total (pensamos particularmente nas vanguardas contemporâneas), as relações dialógicas sempre existem, mesmo que por negação. Atitudes irreverentes, por exemplo, tão comuns principalmente nas artes visuais, sempre têm como pano de fundo um ou mais gêneros artísticos, modos específicos de fazer arte, que serão negados. Quando Duchamp coloca um mictório no museu e diz tratar-se de uma obra de arte não está criando um novo gênero artístico, mas negando qualidades caras aos gêneros considerados legítimos na época, como a ideia clássica de beleza ou do valor artesanal da arte. É apenas em relação às obras negadas que a sua "obra" faz sentido. Mesmo que depois disso os ready-made tenham pululado no mundo das artes visuais contemporâneas, a atitude dessas novas criações, tal como o mictório inaugural, foi sempre confrontar uma proposta artística existente. O mesmo pode ser dito em relação às músicas que recusam, por exemplo, os instrumentos musicais tradicionais, criando suas próprias fontes sonoras, como no caso das músicas eletroacústicas. A originalidade dessas produções só pode ser devidamente apreciada dialogicamente em relação à música tradicional. Um outro exemplo musical bastante conhecido dessa relação "negativa" é o de John Cage, com sua obra "4'33", na qual o músico fica em silêncio completo (negando a qualidade sonora da música) por quatro minutos e trinta e três segundos.

O monologismo puro, ou seja, aquilo que não estabelece relações com nada anterior ou próximo a ele, visto por Bakhtin como impossível na língua, também nos parece impossível na música ou em qualquer outra linguagem 
artística, já que estas se valem sempre, senão de regras, pelo menos de técnicas e materiais já existentes, estabelecidos e significados social e culturalmente.

Contudo, isso não significa que o material em si seja significativo por natureza. Ao contrário, para Bakhtin o material é neutro e por isso pode servir a qualquer sistema ideológico: o valor de um signo é sempre instituído numa relação social ${ }^{8}$. Acontece, porém, na música, que alguns signos, pela recorrência do uso em determinados contextos, vão se "estetizando", cristalizando determinados significados de tal modo que esses significados passam a ser tidos como intrínsecos ao próprio material ou ao elemento frequentemente a eles ligado. É o caso, por exemplo, de determinadas associações historicamente construídas, como entre o modo maior e o caráter alegre; ou o modo menor e o caráter triste das músicas. Ou então, estendendo para as artes visuais, de determinadas associações entre cores e estados de espírito. Diferentemente da língua, porém, esses significados recorrentes não chegam a poder constituir qualquer coisa parecida com um dicionário, por exemplo. Por sua natureza não conceitual, não há como fixar significados na arte dessa maneira. Os significados mais estáveis na arte podem ser sempre atribuídos a certas convenções histórica e geograficamente bem delimitadas, o que acusa suas condições de provisoriedade.

As poéticas de vanguarda tentam fugir ao máximo do uso de signos cristalizados culturalmente, mas, conforme já dito, isso não significa que as relações dialógicas não existam, não se estabeleçam. Tomemos outro exemplo. 0 grupo de percussão Stomp $p^{9}$ apresenta uma proposta estética na qual, ao invés de instrumentos musicais, são usados objetos do cotidiano (baldes, vassouras, talheres, tampas de metal etc.) como fonte sonora. Estaria esse grupo (e outros que usam recursos semelhantes) criando um novo gênero? À parte da negação das fontes sonoras tradicionais, onde estão as relações dialógicas nesse tipo de proposta? Para responder a essa questão, é necessário estabelecer uma distinção

\footnotetext{
${ }^{8}$ Assinala-se que também para Voloshinov (Bakhtin/Voloshinov 2002) a questão ideológica está intimamente ligada à vida, aos valores que são atribuídos coletivamente aos signos e, portanto, conectada aos vários níveis de organização desses conjuntos de signos: inferiores, como as falas cotidianas, e superiores, como os sistemas artístico, científico, econômico etc.

${ }^{9}$ Disponível em: http://www.youtube.com/watch?v=ik8jlCj8juc (acessado em 10/09/2011)
} 
que Bakhtin faz entre gêneros de discurso primários e gêneros de discurso secundários. Os primeiros, mais simples, são os responsáveis pela comunicação cotidiana espontânea (são ligados aos sistemas ideológicos inferiores, menos sistematizados, citados acima). Os segundos, mais elaborados, pertencem aos chamados "sistemas ideológicos organizados" (arte, ciência, política etc.) e são constituídos a partir da absorção e transmutação dos gêneros primários. Por analogia, podemos dizer que, na música, os gêneros primários dizem respeito aos sons "desorganizados" presentes na vida cotidiana e os gêneros secundários equivalem às músicas propriamente ditas, com um mais alto grau de organização. Um olhar bakhtiniano para o Stomp nos permite interpretar o que o grupo propõe como uma espécie de estetização do cotidiano, uma organização do que é, por natureza, caótico. A relação dialógica que se estabelece, nesse caso, podemos dizer que é entre o gênero musical primário e um gênero musical secundário (em termos de sonoridade, o Stomp nos parece bem próximo ao gênero da música popular instrumental).

No extremo oposto às vanguardas eruditas, certa música de massa trabalha basicamente com signos recorrentes, com significados praticamente fixos (os chamados clichês). Como comumente a intenção é garantir um entendimento e uma aceitação mais imediata em larga escala, não há aspiração a monologismos, ou muito espaço para experimentações. Mais do que dialogia, nesse caso a repetição de fórmulas torna-se a regra ${ }^{10}$.

A possibilidade de pensar a dialogia na música, de acordo com a nossa visão, é uma das contribuições mais significativas que a perspectiva do Círculo de Bakhtin oferece, pois permite uma reinterpretação ampliada das obras a partir de critérios de significação e não limitada a apenas critérios formais ${ }^{11}$ ou cronológicos,

\footnotetext{
${ }^{10}$ É bom que se enfatize o fato de que a música de massa também se compõe de inúmeras manifestações que carregam graus diferenciados de inventividade, ou de padronização. Pode-se perceber, também nessa área, desde empreendimentos bem sucedidos no quesito "inovação" até as repetições enfadonhas de simples justaposições dos mesmos elementos.

11 Vale esclarecer que não desmerecemos as análises formais. Consideramos que elas cumprem uma função indispensável mas não suficiente quando o foco é o discurso musical. Lembramos ainda que o próprio Bakhtin considerava a análise formal linguística um momento importante da compreensão da linguagem: "Bakhtin dirá, sempre, que o sistema
} 
como habitualmente é feito (como o caso de várias histórias da música, que se preocupam mais em organizar cronologicamente o aparecimento de obras, autores, escolas e estilos). Vejamos mais detidamente esse aspecto.

\subsection{Dialogia e efeitos de sentido na música}

Pensar a música a partir de uma perspectiva discursiva é tomar como central a questão da significação. Com o objetivo de entender os processos de significação na língua, Voloshinov (Bakhtin/Voloshinov 2002, p. 93-94) estabelece a distinção entre signo e sinal. Segundo sua teoria, o sinal é unívoco, tem sempre o mesmo significado independente do contexto e necessita apenas ser reconhecido. Já o signo precisa ser compreendido, pois seu significado está totalmente orientado pelo contexto, é polissêmico por natureza. Os mesmos elementos, num discurso, têm simultaneamente uma dimensão sinalética e uma dimensão sígnica. Numa música, por exemplo, as notas, acordes, cadências etc. constituem a dimensão sinalética da obra, pois exigem apenas uma atitude de reconhecimento. A significação musical, entretanto, não se reduz a esses sinais, embora os pressuponha, pois esses mesmos elementos, no decorrer do discurso musical, tornam-se signos, cujos significados estão orientados pelo contexto específico da obra, contexto esse que inclui não apenas um enunciado (no caso, a própria obra), mas toda a cadeia discursiva na qual essa obra em questão se coloca. Entender os efeitos de sentido que se produzem em uma música, portanto, é mobilizar as relações dialógicas, é estabelecer uma rede de conexões, é fazer emergir as diversas vozes que constituem, por vezes de maneira oculta, os enunciados musicais. Podemos dizer que a assimilação ideal da música se dá quando o sinal é absorvido pelo signo, o reconhecimento pela compreensão.

Bakhtin considera a linguagem plurilinguística por natureza, na medida em que todo enunciado faz ecoar outras vozes, ouvidas antes dele e por ele

é incapaz de fundar qualquer axiologia, embora se mantenha presente, como pressuposto, em toda axiologia" (Tezza, 2003, p. 195, grifos nossos). 
apropriadas, tornadas próprias. A linguagem é também heterogênea, ou seja, resultado da interação entre vários modos de compreender e valorizar os mesmos enunciados; processo que Faraco (2009) denomina como "heteroglossia dialogizada" (p. 58), resultado se sistemas plurais e simultâneos (sobrepostos) de valorização e significado que as linguagens carregam. Por essa razão, a absorção de outras vozes na minha fala se dá de forma desigual, assimétrica, o que permite um resultado "particular" de enunciação, mesmo que ela seja construída por intermédio da palavra do outro.

Pensamos que essas duas noções, de plurilinguismo e de heteroglossia desenvolvidas pelo Círculo de Bakhtin se aplicam igualmente à música e, muito fortemente, também a outras linguagens artísticas, pois, em toda obra, outra obra (ou outras obras) sempre se faz presente, seja de maneira implícita ou explícita. E, com relação a isso, é interessante como algumas obras, particularmente, talvez por alguma característica peculiar, acabaram suscitando muitas respostas artísticas. Citemos, a título de ilustração, alguns casos. Nas artes visuais, temos, por exemplo, o caso do quadro "O Angelus", de Millet ${ }^{12}$, que só de Salvador Dali teve pelo menos cinco respostas pictóricas ("Atavismo ao Crepúsculo"13, "Angelus arquitetônico de Millet"14, "Reminiscência Arqueológica do Angelus de Millet"15, "Gala e o Angelus de Millet antes da Chegada Iminente da Anamorfose Cônica"16 e "O Angelus de Gala"17), além de um ensaio escrito. Embora essas obras possam ser apreciadas sem o conhecimento prévio de suas referências, parece-nos que a possibilidade de estabelecer conexão com a obra de Millet (bem como com toda a

\footnotetext{
12 Disponível em: http://www.esec-josefa-obidos.rcts.pt/cr/ha/seculo_19/naturalismo.htm (acessado em 10/09/2011)

13 Disponível em: http://www.passeiweb.com/saiba_mais/arte_cultura/galeria/open_art/973 (acessado em 10/09/2011)

14 Disponível em: http://www.virtualdali.com/33MilletsArchitectural.html (acessado em 10/09/2011)

15 Disponível em: http://www.virtualdali.com/35ArchaeologicalReminiscences.html (acessado em 10/09/2011)

${ }^{16}$ Disponível em: http://www.virtualdali.com/33GalaAndTheAngelusOfMille.html (acessado em 10/09/2011)

17 Disponível em: http://www.virtualdali.com/35portraitofgala.html (acessado em 10/09/2011)
} 
história que a cerca) amplia e enriquece bastante a fruição, dá outro sentido aos signos pictóricos ali colocados, pois explicita o contexto, a cadeia comunicativa artística na qual essas obras se inserem.

No caso da música, um exemplo bastante conhecido é o Caprice n. 24, Op.1 para violino de Paganini, música que serviu de mote a inúmeras obras. Só para ficar nos compositores mais conhecidos, Brahms e Liszt compuseram temas e variações para piano, e Rachmaninov compôs a famosa Rapsódia para Piano e Orquestra sobre um Tema de Paganini Op. 43. Podemos dizer que essas obras foram respostas pessoais dos compositores à obra original de Paganini.

É importante assinalar que essa multiplicidade de vozes que, em maior ou menor grau, ecoam nas obras não é privilégio da arte erudita e muito menos de uma ou outra linguagem em particular, pois fazem parte dos próprios princípios constitutivos da arte, segundo o que sustentamos, tanto quanto dos da língua. Tomemos alguns exemplos em outros âmbitos artísticos.

$\mathrm{Na}$ dança podemos citar a coreografia Retrato em branco e preto do grupo Quasar Cia de Dança ${ }^{18}$. Nesta peça, construída sobre a interpretação de Elis Regina da música "Retrato em branco e preto" de Tom Jobim e Chico Buarque de Holanda, podemos perceber um plurilinguismo constituído por uma confluência de "respostas". Primeiramente pelo fato da coreografia ser construída na forma de pax de deux, característico do balé clássico do século XIX, aqui numa confirmação de uma forma tradicional pela sua atualização. Um segundo ponto é a utilização de uma música popular contrapondo-se a uma coreografia que exala um certo hálito de balé clássico, muito embora Tom Jobim, Chico Buarque e Elis Regina se localizem numa esfera sofisticada da música popular (o próprio Tom Jobim goza atualmente do status de maestro equivalente a qualquer maestro do gênero erudito), numa gravação considerada antológica por muitos críticos e estudiosos da música popular brasileira, num esforço que corrobora um movimento muito comum nas artes do Brasil de "eruditizar" o popular e "popularizar" o erudito. E um terceiro e último ponto a ser notado, sobre a própria dança, é a escolha de

18 Disponível em: http://www.youtube.com/watch?v=FzMDwWtm0s0 (acessado em 10/09/2011) 
uma estética contemporânea, na qual estão ausentes as simetrias características do balé, e são enfatizadas as formas distorcidas e assimétricas do corpo, as dinâmicas abruptas e uma variação de tônus mais características da dança contemporânea, para concretização de todas essas relações dialógicas.

Ainda temos outro exemplo, na área da música popular, na versão que César Camargo Mariano e Hélio Delmiro gravaram da música “Carinhoso” de Pixinguinha ${ }^{19}$. Aqui também são várias as confluências responsivas. Primeiro a homenagem ao maestro Pixinguinha, um dos pais do choro e da música instrumental brasileira, executando uma das suas peças mais conhecidas. Depois, a formação camerística num duo de piano elétrico e violão de cordas de aço que remete diretamente à tradição camerística da música erudita, evidentemente transgredida pelos instrumentos semi-eletrificados que ambos utilizam na gravação. E por fim o arranjo elaborado, que conta com uma harmonização de caráter jazzístico, com a alteração do ritmo tradicional do choro para um ritmo mais próximo a uma balada de rhythm and blues americana (pelo menos na apresentação do tema principal), além da construção de uma introdução e uma ponte entre as duas partes principais da música que evocam um estilo mais seresteiro, de um gênero popular brasileiro mais antigo, embora aparentado ao choro, tudo numa ambiência mais contemporânea de sonoridades (como acordes dissonantes, progressões harmônicas menos usuais etc.).

Podemos ver, através desses rápidos exemplos, que a abordagem discursiva da música e da arte permite enfatizar aspectos da criação artística que evidenciam como os fatores contextuais estão intrinsecamente ligados às poéticas. As obras absorvem o que está “fora” delas, e o "fora”, o “contexto”, é modificado pela aparição da obra (do “dentro”), num fenômeno dialético que o Círculo chama de refração. Os artistas são capazes de criar não apenas porque são “inspirados" ou porque dispõem de técnicas e linguagens, mas sobretudo porque dispõem de gêneros e acervos de referências artísticas com as quais vão dialogar

\footnotetext{
19 Disponível numa versão solo em: http://www.youtube.com/watch?v=VcvEZwd3Upc (acessado em 10/09/2011)
} 
em suas criações. Cada obra de arte é pluri-significativa, plurilinguística (Faraco, 2009, p. 58), e faz ecoar muitos outros enunciados artísticos.

\section{A análise discursiva da música: um exemplo}

Dito isto, ainda assim aparecem muitas dúvidas quanto aos procedimentos de abordagem da arte por meio desta perspectiva. Não pretendemos esgotar todas as possibilidades discursivas das obras musicais, mesmo porque esta perspectiva sustentada pelo Círculo de Bakhtin não se mostra como um sistema fechado de procedimentos analíticos. Ao contrário, ela pretende explicitar eventos em processo (como a língua falada) e por conta disto oferece ao pesquisador ou ao analista uma área aberta de possibilidades, um cenário ou ambiente de onde é possível observar e interpretar fenômenos dinâmicos, eventuais, efêmeros, no nosso entender uma conduta adequada principalmente para as artes chamadas do tempo (as quais englobam, além da própria música, teatro, dança, cinema, vídeo, performance etc.), mas que também dão conta mais ou menos facilmente de outras linguagens artísticas.

Para tentarmos esclarecer um pouco melhor o que entendemos por discursividade na música, tentaremos ilustrar alguns pontos de dúvidas recorrentes entre nossos alunos nos cursos ministrados sobre o assunto. E para isso utilizaremos um exemplo particular: a obra musical já citada antes "Quadros de uma Exposição", de Modest Mussorgsky.

Esta obra foi escrita em 1874, numa homenagem de Mussorgsky ao seu amigo morto um ano antes, Viktor Hartmann, pintor e arquiteto. Tendo como base alguns quadros escolhidos numa exposição dos quadros de Hartmann em São Petersburgo, Mussorgsky tentou interpretá-los com sua música de piano (posteriormente orquestrada por Maurice Ravel). Aqui já é possível inferir uma primeira atitude responsiva de Mussorgsky com relação aos quadros de Hartmann. Ainda que a obra do pintor possa ser tomada como um conjunto discursivo, o enunciado ao qual Mussorgsky responde é a exposição - podemos dizer: já um recorte de suas obras organizadas numa galeria a partir de alguns critérios de 
escolha (das obras) e de disposição (a distribuição dos quadros no espaço). A partir desse enunciado específico, Mussorgsky organiza uma nova escolha (a dos quadros que por ele seriam musicados) e uma nova distribuição (já que transforma uma experiência espaço-temporal e visual numa série de peças musicais de caráter temporal, apresentadas numa sucessão linear). Neste caso temos uma atitude responsiva que acontece numa linguagem diferenciada daquela do enunciado ao qual ela responde. Ou seja, a música que responde à pintura.

Para a realização da peça, além dos onze quadros escolhidos para as cenas musicais ("Gnomus"; "Il vecchio castelo"; "Tuileries"; "Bydlo"; "Ballet des Petits Poussins dans leurs Coques"; "Samuel Goldenberg et Schmuyle"; "Limoges, Le Marche"; "Catacombae, Sepulcrum Romanum"; "Cum Mortuis in Língua Mortua”; "La Cabane de Baba-Yaga sur de Pattes de Poule"; "La Grande Porte de Kiev"), Mussorgsky incluiu uma série de cinco "Promedades", ou seja "passeios" (cujo tema reaparece inserido em "Catacombae, Sepulcrum Romanum" e em "La Grande Porte de Kiev"), com um sentido duplo: primeiramente representando o movimento do passeio pela exposição, ou seja, os momentos entre os quadros, e, em segundo, como ponto de referência que reforça, pela repetição de seu tema recorrente, a coesão e coerência arquitetônica da peça. Esta é uma das dificuldades, na estruturação de grupos de peças mais ou menos independentes, que enfrentam os compositores, como é o caso de "Quadros de uma Exposição". A característica fragmentária desse tipo de obra (como é também o caso das suítes, por exemplo) implica no perigo de não se estabelecer nenhuma conexão maior entre suas partes além do fato de se apresentarem juntas, em sequência. Mussorgsky escapa dessa ameaça, em parte, pela inclusão desses interlúdios, que chamou de "Promenade" e que estabelecem pontos de identificação importantes para o ouvinte na estrutura da peça como um todo.

Além das inovações musicais, que não iremos aprofundar aqui mas que caminham para a dissolução da tonalidade e da ampliação das possibilidades pianísticas, inovadoras para a época, e que podem também ser consideradas como respostas do compositor ao estado mais geral da música no seu tempo, Mussorgsky construiu essa espécie de conjunto de pequenas peças num formato 
muito semelhante às atuais trilhas sonoras de filmes. No próprio caráter condensado e monotemático (seria melhor dizer "monoclimático") de cada peça é possível inferir uma intenção visual, quase que esboçando um ambiente sonoro para cada quadro em questão, como se fosse uma trilha filmográfica para cada imagem. Esta aproximação, é importante assinalar, só é possível fazer no campo das significações, no nível dos discursos, já que o cinema só viria a ser difundido algum tempo depois, com a primeira projeção dos irmãos Lumière em Paris em 1895. Entretanto, ficamos razoavelmente à vontade para fazê-la, já que, para o Círculo de Bakhtin, a distância no tempo não impede a construção de pontes entre enunciados que guardam proximidade de sentido. Nas palavras de Bakhtin (2003):

Dois enunciados alheios confrontados, que não se conhecem e toquem levemente o mesmo tema (ideia), entram inevitavelmente em relações dialógicas entre si. Eles se tocam no território do tema comum, do pensamento comum (p. 320).

Com a complementação de Faraco (2009):

Mesmo enunciados separados um do outro no tempo e no espaço e que nada sabem um do outro, se confrontados no plano do sentido, revelarão relações dialógicas. E isso em qualquer ponto do vasto universo da criação ideológica, do intercâmbio sociocultural (p. 65).

Mas não paramos aí. Para além da resposta de Mussorgsky à Hartmann, a própria peça de Mussorgsky inspirou novos enunciados. A orquestração da peça (originalmente escrita para piano solo) pelo compositor Maurice Ravel em 1922 configura-se numa atitude responsiva deste à Mussorgsky. Contudo foi a orquestração de Ravel que fez com que a peça fosse difundida e se tornasse uma das composições mais conhecidas daquele compositor.

Ravel tomou como base expressiva, para sua orquestração, certas características deduzidas da sonoridade pianística, na versão por ele tomada como enunciado, extraída do instrumento por Mussorgsky. Podemos dizer que Ravel organizou, portanto, seu enunciado orquestral levando em conta o caráter 
discursivo dessa versão pianística. Entretanto, o caráter responsivo de certa forma exigiu que sua adaptação para orquestra excluísse um dos interlúdios ("Promenade") finais e acrescentasse, por conta da necessidade que Ravel parece ter sentido de preservar algumas características pianísticas da peça, alguns outros eventos musicais não prescritos por Mussorgsky na sua partitura.

A rede responsiva no qual se insere os "Quadros de uma Exposição" ainda permanece em expansão e inclui o diálogo entre gêneros musicais distintos. Por um lado, o grupo de rock progressivo Emerson, Lake and Palmer, em 1971, gravou uma versão rock da obra. Nesta versão apenas algumas partes da peça foram preservadas (três das "Promenade", "The gnome", "The old castle", "The hut of Baba Yaga”, "The great gates of Kiev"), além da inclusão de outras novas ("The sage", "Blues variations", "The curse of Baba Yaga”, "Nutcracker"). Nos termos do Círculo bakhtiniano, podemos dizer que houve uma reestruturação criativa do enunciado original através de um processo de fragmentação e improvisação. O grau de liberdade inventiva cultivado pela música popular, e particularmente pelo rock progressivo dos anos 1970-80, se mostra bem maior do que o grau de liberdade tolerado pelo gênero erudito ${ }^{20}$. Basta compararmos a orquestração de Ravel, na qual certas liberdades foram tomadas, com a versão quase totalmente improvisada do Emerson, Lake and Palmer. A improvisação característica dos grupos de rock está presente em praticamente todas as peças nesta versão de "Pictures at an Exhibition" (como foi chamado o disco gravado pelo grupo com a obra), o que era ausente na versão original, além da grande mudança na instrumentação (o grupo se compõe de teclados eletrônicos - Keith Emerson -, baixo, guitarra e canto - Greg Lake - e bateria - Carl Palmer). Em todo caso, a atitude responsiva do Emerson, Lake and Palmer preservou uma proximidade muito grande com a peça original, a ponto de podermos identificá-la como uma "versão” dos “Quadros de uma Exposição”.

\footnotetext{
${ }^{20}$ Vale lembrar que, para o Círculo de Bakhtin, os gêneros de discurso estão ligados a esferas da atividade humana. Nesse sentido, as versões ligadas aos gêneros musicais populares de certo modo refletem posturas típicas dessa forma de atividade musical. Enquanto o músico erudito se forma e atua no rigor da tradição e do universo da escrita musical, o músico popular se forma e atua numa esfera musical da oralidade e da iniciativa.
} 
Uma outra resposta a Mussorgsky aconteceu em 1975, quando o tecladista japonês Isao Tomita lançou no mercado uma versão dos "Quadros..." com teclados eletrônicos. Neste caso particular um outro gênero de discurso musical entra em jogo: o gênero pop. Os anos 1970 foram marcados pela invenção e difusão dos teclados eletrônicos, frutos de possibilidades tecnológicas recém desenvolvidas em estúdios de rádio e gravação. Portanto, a intenção do tecladista Tomita, assim como a de Wendy Carlos e de vários outros músicos na mesma época, parecia ser, entre outras coisas, a confirmação do teclado eletrônico como um instrumento versátil e completo. Certamente esta deve ter sido uma das razões para o aparecimento de inúmeras obras eruditas executadas em timbres eletrônicos (como é o caso da "Nona Sinfonia" de Beethoven e o "Cravo bem Temperado", gravados por Wendy Carlos; as suítes "Pássaro de Fogo", de Stravinsky, "The Planets", de Holst, gravados por Isao Tomita; no Brasil temos o caso de Egberto Gismonti que, no disco Trem Caipira de 1985, interpretou com teclado eletrônico várias peças de Villa-Lobos, tais como "Canção do carreteiro Seresta n०8", "Bachianas Brasileiras n. 4", "Pobre Cega", das 16 Cirandas). Diferente de Emerson, Lake and Palmer, Tomita respeitou a partitura de Mussorgsky criando uma instrumentação com timbres eletrônicos bastante original. Aqui também a proximidade das versões, resultante de uma situação em que a transgressão tinha tolerância limitada, faz com que, no nível da significação, a enunciação responsiva de Tomita possa ser considerada também como uma nova versão (ou interpretação) da mesma peça.

Mas a cadeia discursiva por onde os "Quadros de uma Exposição" transita está longe de se esgotar. São inúmeras as apropriações e recortes desta peça (que já mostramos ser um enunciado em resposta a uma exposição de quadros) feitas por outros campos artísticos, como peças de teatro, cinema e TV (lembramo-nos de um grupo de teatro de rua italiano que visitou a Unicamp na década de 1980 e que usou como interlúdio musical entre seus números o tema "Promenade" inicial da peça), ou mesmo por outras áreas de atividades, como a educação ou a musicoterapia.

Muitas outras dimensões ainda poderiam ser abarcadas por esse tipo de análise. As variadas entonações expressivas presentes nas inúmeras interpretações 
dos "Quadros..." feitas por vários pianistas, por exemplo, que mostrariam de modo mais explícito as ênfases de articulação, os jogos de intensidades, as variações de andamento particulares de cada "pronúncia" de um mesmo texto ${ }^{21}$. As várias interpretações orquestrais da mesma peça, inclusive a comparação entre a orquestração de Ravel, mais conhecida, e a orquestração do próprio Mussorgsky poderiam desnudar o modo como as várias nuances distintivas entre as concepções orquestrais de uma mesma ideia musical alteram a significação dessa ideia.

As apropriações, já citadas acima, de trechos da peça (fragmentos de um enunciado), como no caso do teatro de rua, de alguma forma explicitam um processo de condensação de significados em que certo trecho de uma obra maior pode adquirir, pelo menos em potência, o poder de desencadear a significação outrora atribuída à peça inteira (o enunciado completo). Para citar alguns casos marcantes desse processo basta lembrar da "Quinta Sinfonia” de Beethoven, na qual a célula inicial já possui existência praticamente autônoma do resto da peça; também o trecho "eu não sou cachorro não" da música homônima de Waldik Soriano, transformada em expressão popular de protesto bem humorado na década de 1970 (Araújo, 2002, p. 235 e ss.); ou ainda as progressões harmônicas, mencionadas por Philip Tagg (2011, p. 10) da música "My sweet lord”22, de George Harrison, identificada por seus alunos em "He's so fine" 23 , do grupo Chiffons, e em "Oh happy day"24, de Edwin Hawkins Singers; e da música "La Bamba"25 (TAGG, 2011, p. 13), de Richie Valens, também identificada em

${ }^{21}$ Sabemos também de uma versão da peça para violão solista, executada por Yamashida Kazuhito, que possui um trecho disponível em: http://www.youtube.com/watch?v=2FNIwmpU7Rk (acessado em 10/09/2011)

22 Disponível em: http://www.youtube.com/watch?v=_Ls8Mhoafn0 (acessado em 10/09/2011)

23 Disponível em: http://www.youtube.com/watch?v=vpAcQrt8-SE (acessado em 10/09/2011)

24 Disponível em: http://www.youtube.com/watch?v=CNQXQKfIJNA\&feature $=$ fvst (acessado em 10/09/2011)

25 Disponível em: http://www.youtube.com/watch?v=Jp6j5HJ-Cok (acessado em 10/09/2011) 
“Guantanamera"26, de José Martí e Josito Fernandes, e "Twist and Shout"27, dos Beatles.

Estes são casos particulares em que alguns elementos característicos de algumas obras adquirem, através das variadas formas de apropriação, recorte e significação pela qual vão passando na cadeia discursiva, a propriedade de representarem a totalidade das obras das quais foram retirados e, assim, sintetizam parte de seus significados coletivos. Para tanto, basta uma breve menção para que a lembrança desses significados venha à tona. Isso acontece porque os elementos tornaram-se enunciados completos, unidades no campo discursivo, da música em funcionamento.

O que tentamos explicitar com o exemplo acima de Quadros de uma Exposição, embora exposto um tanto rapidamente, é que o montante de relações implícitas (a dialogia, nos termos do Círculo) em qualquer obra, seja ela musical, teatral, coreográfica, cinematográfica, pictórica, escultural, literária, é praticamente infinito quando abordado a partir da perspectiva da discursividade, no sentido que o Círculo bakhtiniano dá ao termo. Muitos outros desdobramentos ainda poderiam ocorrer mantendo como base a mesma peça musical. As direções possíveis de identificação das relações dialógicas abrem-se para todos os lados: para trás (os enunciados antecedentes para os quais a obra em questão responde), para frente (os enunciados que respondem à obra em questão) e para os lados (os outros enunciados partícipes do mesmo momento histórico da obra em questão).

Isto inclui também, e principalmente, as relações dialógicas presentes entre o interior da obra, sua estrutura, elementos e modos de articulação e encadeamento, e o exterior, as condições contextuais de possibilidades. O que nos dá uma perspectiva de superação da dicotomia "dentro" e "fora" do campo artístico, dentro e fora da obra de arte.

\footnotetext{
26 Disponível em: http://www.youtube.com/watch?v=vmoP7_cdlTw\&feature $=$ fvst (acessado em 10/09/2011)

27 Disponível em: http://www.youtube.com/watch?v=pVIr4g5-r18 (acessado em 10/09/2011)
} 


\section{Considerações finais: outros horizontes para essa abordagem}

Neste artigo apresentamos uma abordagem epistemológica que busca diluir algumas dicotomias ainda arraigadas no pensamento sobre a música. A perspectiva discursiva do Círculo de Bakhtin, ao articular, de modo inseparável, enunciados e situações enunciativas, permite verificar, de um lado, como as condições externas dão origem a propostas estéticas específicas e, de outro, como essas propostas ensejam expressões, ideias e até mesmo atitudes que muitas vezes ultrapassam suas fronteiras internas e se estabelecem como referências para a vida, a sociedade e a cultura. E essa é uma característica bastante peculiar desta abordagem, que se aproxima, por exemplo, de alguns autores da música, como é o caso de Jean-Jacques Nattiez (2005) ou Philip Tagg (2011), que abordam as músicas dos dois pontos de vista (dentro e fora, música e contexto) de forma complementar e, de modo geral, em fases distintas. Nossa tentativa, entretanto, é tentar eliminar a necessidade de "etapas de análise", buscando as relações de cumplicidade mútua entre esses pontos de vista, de tal modo que seja impossível considerar um desconsiderando o outro. Encontramos eco nessa proposta, por exemplo, em Seincman (2008), que também enfatiza as relações discursivas na música e na arte.

Muito embora nosso caminho reflexivo nessa direção ainda esteja no início e muitas pesquisas ainda precisem ser feitas para confirmá-lo, a perspectiva discursiva mostra sinais positivos também ao jogar algumas luzes nas nossas práticas educativas e reflexivas sobre as artes em geral e sobre a música em particular. Para além do campo analítico, pensamos que esse modo de entender a música seja promissor também para o campo educacional e para os diálogos entre a música e outras áreas de atividades, tais como o teatro, a dança e a educação física, dentre várias outras.

O fato de concebermos as músicas como enunciados e o campo musical como uma cadeia discursiva permite uma revisão radical dos procedimentos que envolvem a participação direta ou indireta da música. Na área educacional, por exemplo, de acordo com esta perspectiva, ficam secundárias as preocupações, por 
exemplo, em "passar conteúdos" ou "desenvolver habilidades" ou "competências" musicais aos alunos. A preocupação principal passa a ser, isso sim, conduzi-los, na medida do possível, pelo terreno das significações musicais, tentando incentivá-los a uma atitude responsiva em relação aos enunciados musicais, seja ela qual for (tocar um instrumento, fazer um desenho, dançar, baixar uma música na internet, compor uma trilha para uma cena de filme, descobrir como se regula uma guitarra, cantar um rap etc.).

Isto acaba também por minimizar a distância entre aulas de música para "leigos" e para "músicos" ou, para denunciar outra falsa dicotomia educacional ideologicamente estabelecida, entre a formação de músicos e a formação de plateia. Em um ou outro caso, é sempre o discurso musical, na sua completude, que é o foco da atenção.

Isto ocorre igualmente quando abordamos as realizações conjuntas, como no caso da criação coletiva de músicos e bailarinos, por exemplo. As preocupações se deslocam dos problemas técnicos, ou da falta de compreensão mútua dos modos respectivos de se expressar artisticamente, para os problemas da construção coletiva de enunciados artísticos (como é o caso das coreografias colaborativas ou das improvisações coletivas). Surge aí a possibilidade de abordagem de uma dimensão responsiva interna, entre as partes envolvidas, ou entre os profissionais participantes.

No que diz respeito ao estímulo a uma atitude responsiva (que o Círculo de Bakhtin considera também compreensiva: "qualquer tipo genuíno de compreensão deve ser ativo, deve conter já o germe de uma resposta" (Bakhtin/Voloshinov 2002, p. 131)), por um lado, num ambiente educativo, a diferença entre músicos e leigos, e por outro, num ambiente artístico colaborativo, a diferença entre músicos e bailarinos, passa a ser não mais o grau de conhecimentos e habilidades (competências) que cada um desenvolve, mas sobretudo a forma da resposta que cada um oferece à situação única da qual participam. 


\section{Referências}

ARAÚJO, Paulo César de. Eu não sou cachorro não. 3.ed. Rio de Janeiro: Record, 2002. 462p.

BAKHTIN, Mikhail (Voloshinov). Marxismo e filosofia da linguagem. 9.ed. São Paulo: Hucitec/Annablume, 2002. 200p.

BAKHTIN, Mikhail. Estética da criação verbal. 3.ed. São Paulo: Martins Fontes, 2000. 512p.

BAKHTIN, Mikhail. Estética da criação verbal. 4.ed. São Paulo: Martins Fontes, 2003. 478p.

BRAIT, Beth (org.). Bakhtin e o círculo. São Paulo: Contexto, 2009. p.208.

BUBNOVA, Tatiana. Sobre as ruínas de "Bakhtin" ou os perigos da isegoria. p.1932. In: PAULA, Luciane de; STAFUZA, Grenissa (orgs.). Circulo de Bakhtin: diálogos in possíveis. Campinas: Mercado de Letras, 2010. p280.

FARACO, Carlos Alberto. Linguagem e diálogo: as ideias linguísticas do Círculo de Bakhtin. São Paulo: Parábola Editorial, 2009. 168p.

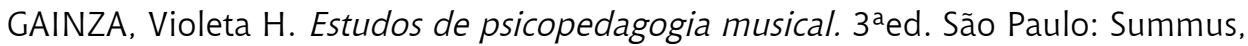
1988. 144p.

GEERTZ, Clifford. O saber local: novos ensaios em antropologia interpretativa. Petrópolis: Vozes, 1997. 368p.

GUYAU, Jean-Marie. A arte do ponto de vista sociológico. São Paulo: Martins, 2009. 692p.

LÉVY-STRAUSS, Claude. Olhar escutar ler. São Paulo: Companhia das Letras, 1997. $152 \mathrm{p}$.

MARCUSE, Herbert. A dimensão estética. Lisboa: Edições 70, 1999. 88p.

MORSON, Gary S.; EMERSON, Caryl. Mikhail Bakhtin: criação de uma prosaística. São Paulo: Editora da Universidade de São Paulo, 2008. 552p.

NATTIEZ, Jean-Jacques. O combate entre Cronos e Orfeu. São Paulo: Via Lettera, 2005. 320p.

PAULA, Luciane de; STAFUZZA, Grenissa (orgs.). O círculo de Bakhtin: teoria inclassificável. Campinas: Mercado das Letras, 2010. 478p.

ROHMER, Eric. Ensaio sobre a noção de profundidade na música: Mozart em Beethoven. Rio de Janeiro: Imago editora, 1997. 240p.

SAID, Edward e BAREMBOIM, Daniel. Paralelos e paradoxos: reflexões sobre música e sociedade. São Paulo: Companhia das Letras, 2003. 192p.

SCHAFER, R. Murray. O ouvido pensante. $2^{\mathrm{a} e d}$. São Paulo: Editora da UNESP, 2000. 400p. 
SEINCMAN, Eduardo. Estética da comunicação musical. São Paulo: Via Lettera, 2008. 160p.

SCHROEDER, Jorge L. O dentro e o fora da música: notas para uma reflexão sobre a apreciação musical. Ensinarte: revista das artes em contexto educativo, Braga: Portugal, vol. 3, 2-14, inverno de 2004.

SCHROEDER, Sílvia C. N. A educação musical na perspectiva da linguagem: revendo concepções e procedimentos. Revista da ABEM, Porto Alegre, vol.21, 4452, mar. 2009.

TAGG, Philip. Análise musical para "não-musos": a percepção popular como base para a compreensão de estruturas e significados musicais. Per Musi, Belo Horizonte, n.23, 7-18, jan/jun 2011.

TEZZA, Cristovão. Entre a prosa e a poesia: Bakhtin e o formalismo russo. Rio de Janeiro: Rocco, 2003.

ZOLBERG, Vera L. Para uma sociologia das artes. São Paulo: Editora Senac São Paulo, 2006. 360p. 